\title{
Inhalation of cold air increases the number of inflammatory cells in the lungs in healthy subjects
}

\author{
K. Larsson*, G. Tornling**, D. Gavhed+, C. Müller-Suur*, L. Palmberg*
}

Inhalation of cold air increases the number of inflammatory cells in the lungs in healthy subjects. K. Larsson, G. Tornling, D. Gavhed, C. Müller-Suur, L. Palmberg. CERS Journals Ltd 1998.

ABSTRACT: Prolonged exposure to cold air may induce a chronic asthma-like condition in healthy subjects as has been demonstrated in cross-country skiers. In the present controlled study, our aim was to elucidate further the link between cold air exposure and airway inflammation by assessing the cellular influx and mediator levels within the airways following acute exposure to cold air.

Bronchoalveolar (BAL) and nasal lavages were performed after exposure to cold air $\left(-23^{\circ} \mathrm{C}\right)$ and normal indoor air $\left(+22^{\circ} \mathrm{C}\right)$ during a light, intermittent work for $2 \mathrm{~h}$ in a cross-over design in eight healthy, nonsmoking, subjects. Analyses of inflammatory cell number, cell activation markers, pro-inflammatory cytokines, albumin and interleukin (IL)-8 in lavage fluids were performed.

The number of granulocytes and of alveolar macrophages in BAL fluid was significantly higher after cold air exposure $(\mathbf{p}<0.05)$. No increase in BAL fluid lymphocytes and no signs of lymphocyte activation in BAL fluid were found. The concentration of IL-8 was unchanged. There were no signs of granulocyte activation (myeloperoxidase, eosinphilic cationic protein) in BAL fluid. Cold air did not influence the number of inflammatory cells or the concentration of albumin and IL-8 in nasal lavage fluid.

In conclusion, exposure to cold air induces an increased number of granulocytes and macrophages in the lower airways in healthy subjects without influencing other inflammatory indices such as cellular activation, plasma leakage and pro-inflammatory cytokines. These findings support the hypothesis that cold air could be of pathogenetic importance in the asthma-like condition previously found in cross-country skiers. Eur Respir J 1998; 12: 825-830.
*Dept of Occupational Medicine, National Institute for Working Life, Solna, Sweden **Division of Respiratory Medicine, Dept of Medicine, Karolinska Institute, Stockholm, Sweden. +Dept of Climate Physiology, National Institute for Working Life, Solna, Sweden.

Correspondence: K. Larsson

Dept of Occupational Medicine

National Institute for Working Life

S-171 84 Solna

Sweden

Fax: 4687309897

Keywords: Cold air granulocytes

macrophages

Received: September 291997

Accepted after revision May 41998

This study was supported by The Swedish Heart-Lung Foundation and GlaxoWellcome.
An increased prevalence of asthma has recently been reported in Swedish cross-country skiers. The skiers have an increased prevalence of asthmatic symptoms $[1,2]$ and bronchial hyperresponsiveness to methacholine [2], characteristics that from a clinical point of view, are usually defined as asthma. The most probable explanation for the high prevalence of asthma in cross-country skiers is the heavy exposure to inspired cold air during training and competition in this branch of sports. Inhalation of cold air may induce a transient increase in bronchial reponsiveness to histamine in healthy subjects [3] and induce bronchoconstriction in asthmatic subjects. It is not clear whether it is the low temperature [4] or the low water content [5] of the inhaled air that is responsible for the bronchoconstrictor effect. Increased bronchial responsiveness in asthma is related to airway inflammation, although there is no evidence for a causal relationship. The clinical condition of many cross-country skiers is thus very similar to asthma, but it is not clear whether morphological changes in the airways of the skiers exhibit the same characteristics as those found in other asthmatic subjects. However, it seems reasonable to postulate that inhalation of cold air in the long run induces airway inflammation. Whether an acute shortterm exposure to cold air induces inflammatory changes in the airway is not known. The transient increase in bron- chial responsiveness [3] induced by acute cold air exposure in healthy subjects may indicate that this is the case.

Short-term effects of cold air on the airways in healthy subjects has not been extensively studied. We have addressed this question in a controlled experiment in which healthy subjects were exposed to cold air or normal indoor air temperature for $2 \mathrm{~h}$ in a cross-over study design. After the exposures, nasal and bronchoalveolar lavages were performed, and we found evidence that acute exposure to cold air increases the number of inflammatory cells in the lower airways (assessed by BAL) in healthy subjects.

\section{Material and methods}

\section{Subjects and study design}

Eight healthy, nonsmoking, subjects (four males) with a mean age of 30 (range 20-43) yrs participated in the study. None had any former or present symptoms of allergy or airway disease. None of the participants had ever reacted with cough, wheeze or dyspnoea to cold air. All participants gave their informed consent and the study was approved by the Ethics Committee of the Karolinska Institute. 
The subjects underwent a clinical investigation with blood-sampling, chest radiograph and nasal lavage 1 week before the study start. On two occasions, 2-3 weeks apart, they participated in an exercise session at a normal indoor temperature $\left(+22^{\circ} \mathrm{C}\right)$ or cold temperature $\left(-23^{\circ} \mathrm{C}\right)$ in a random order. Nasal lavages were performed before the first exposure and 4 and $20 \mathrm{~h}$ after the start of the exposure. A bronchoalveolar lavage (BAL) was performed $20 \mathrm{~h}$ after the start of the exposure.

\section{Exercise protocol}

Each exercise session lasted for $2 \mathrm{~h}$, divided into four exercise-rest cycles, during which the subjects ran on a motor-driven treadmill for $15 \mathrm{~min}$ and rested for $15 \mathrm{~min}$ in the sitting position. The subjects selected a moderately high running speed which they considered themselves to be able to maintain throughout all four exercise periods. The same individual speed selected at the first experimental day was applied at the exercise session on the second experimental day. The order of exercise and rest was randomized. The oxygen consumption $\left(V^{\prime} \mathrm{O}_{2}\right)$ was measured during the last 3-5 min of the first and the last, i.e. fourth, cycle. The cardiac frequency was measured continuously, and the collected values were averaged over $1 \mathrm{~min}$. Ratings of perceived exertion (RPE) on the Borg RPE scale were given immediately before the $V^{\prime} \mathrm{O}_{2}$ measurements.

\section{Bronchoalveolar and nasal lavage}

A bronchoscopy was performed through the nose with a flexible fibreoptic bronchoscope (Olympus Type 4B2, Tokyo, Japan) under local anaesthesia with lignocaine (Xylocain(®), Astra, Södertälje, Sweden) after premedication with morphine-scopolamine. The bronchoscope was wedged in a middle lobe subsegmental bronchus, and 250 $\mathrm{mL}$ sterile saline at $+37^{\circ} \mathrm{C}$ were instilled in five aliquots of $50 \mathrm{~mL}$. After each instillation, the fluid was gently aspirated and collected in a siliconized plastic bottle kept on ice and centrifuged at $200 \times \mathrm{g}$ for $10 \mathrm{~min}$ at $+4^{\circ} \mathrm{C}$. The supernatant was kept frozen at $-70^{\circ} \mathrm{C}$ until analysis. The pellet was resuspended in RPMI medium, and the cells were counted in a Bürker chamber.

A nasal lavage was performed according to the methods described by BASCOM and PIPKORN [6, 7] with minor modifications. The subject flexed the neck $45^{\circ}$ backwards and closed the soft palate while $5 \mathrm{~mL} 0.9 \% \mathrm{NaCl}$ was instilled into one nostril, using a needleless syringe. After $10 \mathrm{~s}$, the neck was flexed forwards, and the liquid was expelled into a plastic basin that was placed on ice during processing. The procedure was repeated on the other side. The volume of the combined lavage portions was measured and centrifuged for $10 \mathrm{~min}$ at $200 \times g$ at $+4^{\circ} \mathrm{C}$ and the supernatant was frozen at $-70^{\circ} \mathrm{C}$ until analysis. The pellet was resuspended in $0.9 \% \mathrm{NaCl}$ with $0.1 \%$ human serum albumin, the cells were counted in a Bürker chamber, and the number of cells of recovered lavage fluid was calculated. Cytocentrifuge-prepared slides were stained with MayGrünwald Giemsa stain, and 300 cells were counted for cell differentials. A number $<100$ cells was considered insufficient to make an accurate differential count.

\section{Analyses}

\section{Cell analyses}

BAL cells were characterized by fluorochrome-conjugated monoclonal antibodies. Ten microlitres of CYTOSTAT/Coulter Clone monoclonal antibody (Coulter Electronics, Hialeah, FL, USA), were added to $100 \mu \mathrm{L}$ aliquots of BAL fluid and incubated for $10 \mathrm{~min}$ at normal room temperature. Lysing of red blood cells, fixation and stabilization of white blood cells was achieved using Coulter ${ }^{\circledR}$ Multi-Q-prep (Coulter Electronics). Monoclonal antibodies (CD69) (Leu-23, Becton and Dickinson, Immunocytometry Systems, San Jose, CA, USA) were diluted and incubated according to the manufacturer's instructions. For the background staining pattern, isotypic controls were performed considering immunoglobulin subclasses. Analyses were carried out by flow cytometry using an EPICS Profile II (Coulter Electronics, ). A cell differential count was performed using CD14-CD45 (Mo2-RD1/Kc56-Fitc). Monoclonal antibodies (CYTO-STAT/Coulter Clone, Coulter Corporation, Miami, FL, USA) recognizing T-cells (CD3 (T3)), T-cell subsets (helper cells, CD4 (T4), suppressor cells CD8 (T8)), B cells (CD19 (B4)) and T-cell activation (early T-cell activation marker, CD69) were used.

\section{Albumin}

Albumin in BAL and nasal lavage fluid was quantified by an inhibition enzyme-linked immunosorbent assay (ELISA) method as previously described [8]. A coefficient of variation $(\mathrm{CV})$ of $<5 \%$ and $10 \%$ for duplicate intraassay and inter-assay samples, respectively, was accepted.

\section{Cytokines}

The interleukin (IL)-8 concentration in lavage fluid was measured in duplicate with an ELISA method using commercial available antibody pairs (capture antibody (MAB208), detection antibody (BAF208) and standard (208-IL-101), R\&D Systems Europe, Abingdon, UK). The lower detection limit of the assay was $6.0 \mathrm{ng} \cdot \mathrm{L}^{-1}$. An intraassay CV $<10 \%$ and an inter-assay CV of $<20 \%$ was accepted for duplicated samples.

The concentration of tumour necrosis factor- $\alpha$ (TNF $\alpha)$ in BAL fluid was measured in duplicate by ELISA. A Quantikine $^{\mathrm{TM}}$ high sensitivity (HS), two site (sandwich) ELISA kit (R\&D systems Europe, Abingdon, UK) was used. The Quantikine TM HS immunoassay used an enzyme amp-lification system with alkaline phosphatase, and the lower detection limit of the assay was $0.5 \mathrm{ng} \cdot \mathrm{L}^{-1}$.

The concentration of IL-6 in BAL fluid was measured with an ELISA method developed in our laboratory. A monoclonal human antibody against IL-6 (R\&D systems, MAB206) was used as a capture antibody, at a concentration of $4 \mathrm{mg} \cdot \mathrm{mL}^{-1}$ (in phosphate-buffered saline (PBS)), which was bound to 96-well microtitre plates (Maxisorp, Nunc, Denmark) overnight at room temperature. After washing, the wells were incubated with a blocking buffer (PBS with $1 \%$ bovine serum albumin (BSA), $5 \%$ sucrose and $0.15 \%$ Kathon $^{\mathrm{TM}}$, Rohm and Haas Co., Philadelphia, PA, USA) for $1 \mathrm{~h}$ at room temperature. After washing, standard dilutions $\left(3-375 \mathrm{pg} \cdot \mathrm{mL}^{-1}\right)$ of recombinant human 
Table 1. - Comparison of lung and heart variables at rest and exercise at two ambient temperatures

\begin{tabular}{|c|c|c|c|c|c|c|c|c|}
\hline & \multicolumn{2}{|c|}{ Rest $22^{\circ} \mathrm{C}$} & \multicolumn{2}{|c|}{ Rest $-23^{\circ} \mathrm{C}$} & \multicolumn{2}{|c|}{ Running $22^{\circ} \mathrm{C}$} & \multicolumn{2}{|c|}{ Running $-23^{\circ} \mathrm{C}$} \\
\hline & 1st cycle & 4th cycle & 1st cycle & 4th cycle & 1st cycle & 4th cycle & 1st cycle & 4th cycle \\
\hline$V^{\prime} \mathrm{E} \mathrm{L} \cdot \mathrm{min}^{-1}$ & $7.9 \pm 0.6$ & $7.9 \pm 0.5$ & $8.7 \pm 0.8$ & $9.6 \pm 1.1$ & $60.8 \pm 6.6$ & $53.2 \pm 4.5$ & $59 \pm 49$ & $59 \pm 4.2$ \\
\hline$V^{\prime} \mathrm{O}_{2} \mathrm{~L} \cdot \mathrm{min}^{-1}$ & $0.28 \pm 0.03$ & $0.29 \pm 0.02$ & $0.30 \pm 0.02$ & $0.33 \pm 0.03$ & $2.43 \pm 0.26$ & $2.17 \pm 0.19$ & $2.14 \pm 0.15$ & $2.19 \pm 0.14$ \\
\hline RQ & $0.88 \pm 0.03$ & $0.84 \pm 0.02$ & $0.86 \pm 0.01$ & $0.84 \pm 0.02$ & $0.95 \pm 0.02$ & $0.93 \pm 0.03$ & $1.02 \pm 0.03$ & $1.03 \pm 0.03$ \\
\hline$f_{C}$ beats $\cdot \mathrm{min}^{-1}$ & - & - & - & - & $160 \pm 6$ & $159 \pm 6$ & $151 \pm 5$ & $154 \pm 6$ \\
\hline RPE & - & - & - & - & $14.3 \pm 0.4$ & $13.6 \pm 0.7$ & $12.3 \pm 0.3$ & $13.1 \pm 0.3$ \\
\hline
\end{tabular}

Difference between cardiac frequency $(f \mathrm{C})$ at the two ambient temperatures was significant $(\mathrm{p}<0.05) . V^{\prime} \mathrm{E}$ : ventilation; $V^{\prime} \mathrm{O}_{2}$ : oxygen consumption; RQ: respiratory quotient; RPE: rating of perceived exercise.

IL-6 (R\&D systems, 206-IL-010) or sample diluted in PBS/0.1\% Tween (dilution buffer) were added to the wells in duplicate, mixed on a shaker and incubated for $2 \mathrm{~h}$ at room temperature. After repeated washing, the detection biotinylated antibody (1:250, R\&D systems, BAF206) in dilution buffer was added and incubated for $2 \mathrm{~h}$ at room temperature. After repeated washing, the conjugate streptavidin-HRP (PQ35580, in-house) was added for a $1 \mathrm{~h}$ incubation. Following washing, the substrate K-blue was added, and the reaction was terminated after $10 \mathrm{~min}$ with $1 \mathrm{M} \mathrm{H}_{2} \mathrm{SO}_{4}$. Absorbance was read at $450 \mathrm{~nm}$ using a Thermomax 250 reader (Molecular Devices, Sunnyvale, CA, USA), and the results were analysed with Softmax ${ }^{\circledR}$ software (Molecular Devices, Sunnyvale, CA, USA). Quantiki$\mathrm{ne}^{\mathrm{TM}}$ serum controls at three different levels were used as calibrators. The lower detection limit of the assay was 3 $\mathrm{ng} \cdot \mathrm{L}^{-1}$. For duplicated samples, an intra-assay $\mathrm{CV}$ of $<10 \%$ and an inter-assay CV of $<20 \%$ was accepted. There was a high correlation $(\mathrm{r}=0.93)$ between the results obtained using the commercial kit and the present method.

\section{Human myeloperoxidase}

Human myeloperoxidase (MPO) in BAL fluid was measured in duplicated samples by Bioxytech ${ }^{\circledR}$ MPO enzyme immunoassay, (OXIS International, R\&D systems Europe, Abingdon, UK) with a lower detection limit of $1.6 \mu \mathrm{g} \cdot \mathrm{L}^{-1}$.

\section{Eosinophil cationic protein}

Eosinophil cationic protein (ECP) in BAL fluid was measured in duplicate according to the manufacturer's in- structions with Pharmacia CAP system ECP FEIA (Pharmacia AB, Uppsala, Sweden) with a lower detection limit of $2 \mu \mathrm{g} \cdot \mathrm{L}^{-1}$.

\section{Statistics}

Results are presented as median (25th-75th percentiles) or mean \pm SEM. Comparisons are calculated using Wilcoxon's signed rank test (for paired observations). Multiple comparisons are corrected with the Bonferroni method. A p-value $<0.05$ is considered significant.

\section{Results}

Exposure data are shown in table 1. None of the participants reported airway symptoms or coughed during or following the exposure to air of normal room temperature or to cold air. The pulmonary ventilation was similar at ambient temperatures at rest and exercise. The total pulmonary ventilation during the 2-h sessions was estimated to approximately 4,000 $\mathrm{L}$ in cold air and 3,900 $\mathrm{L}$ at room temperature. The oxygen consumption at rest and exercise was similar, and the respiratory quotients were high and similar at exercise at both temperatures. The cardiac frequency was lower when exercise was performed at $-23^{\circ} \mathrm{C}$ compared with $+22^{\circ} \mathrm{C},(\mathrm{p}<0.05)$. The range of ratings of perceived exertion was "fairly light" (11) to "hard" (16).

The BAL fluid recovery was $179 \pm 8 \mathrm{~mL}$ after exposure to normal indoor air and $175 \pm 9 \mathrm{~mL}$ after exposure to cold air. The number of BAL fluid granulocytes was higher in all subjects after exposure to cold air $\left(6.8(4.4-8.2) \times 10^{6}\right.$ cells $\left.\cdot \mathrm{L}^{-1}\right)$ compared with room temperature (1.8 (1.7-4.2) $\times 10^{6}$ cells $\cdot \mathrm{L}^{-1}, \mathrm{p}=0.01$, fig. 1$)$. Also, the number of BAL fluid alveolar macrophages was significantly higher after a)

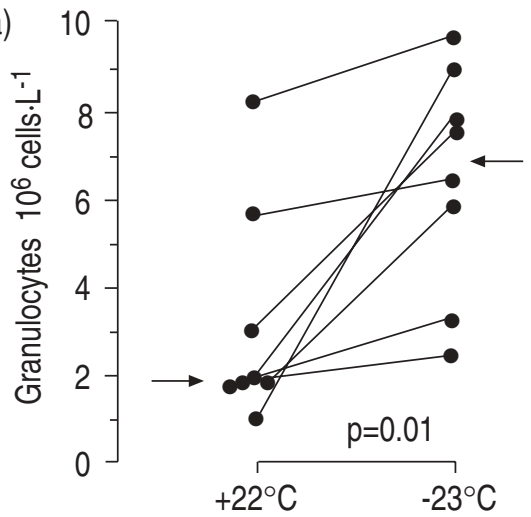

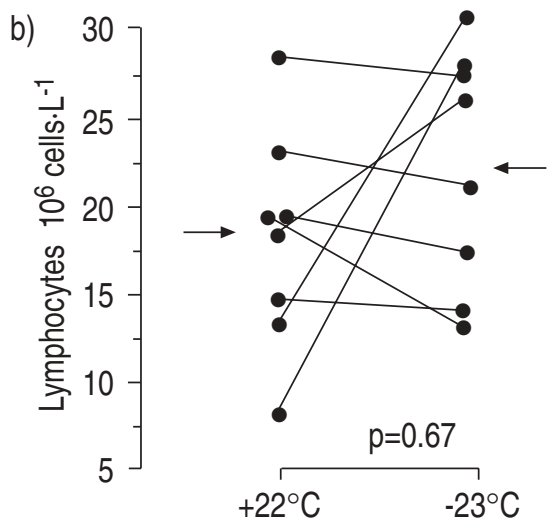

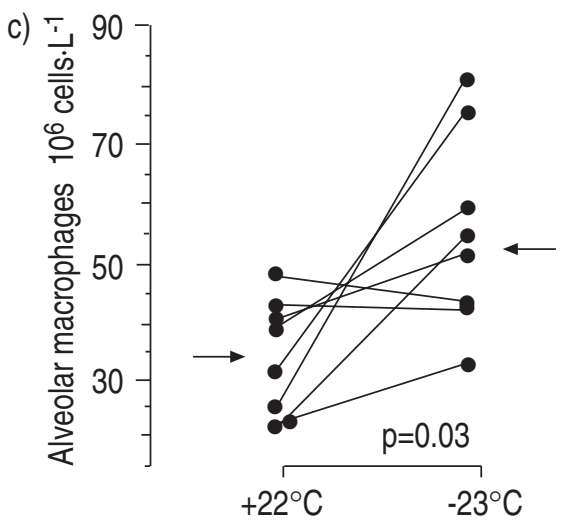

Fig. 1. - Concentrations of a) granulocytes, b) lymphocytes and c) alveolar macrophages in bronchoalveolar lavage fluid $20 \mathrm{~h}$ after exposure to cold air $\left(-23^{\circ} \mathrm{C}\right)$ and air of normal indoor temperature $\left(+22^{\circ} \mathrm{C}\right)$ in eight healthy subjects. Arrows indicate the median values. 

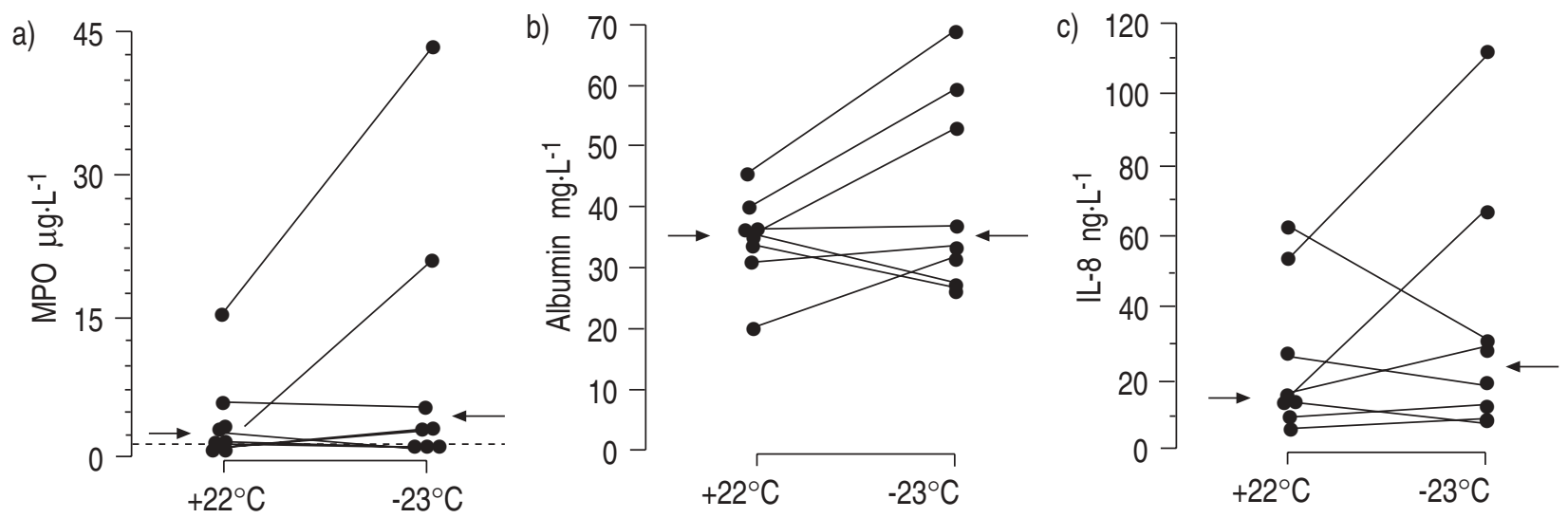

Fig. 2. - a) Human myeloperoxidase (MPO), b) albumin and c) interleukin (IL)-8 concentrations in bronchoalveolar lavage fluid in eight healthy subjects exposed to air of normal indoor temperature $\left(+22^{\circ} \mathrm{C}\right)$ and cold air $\left(-23^{\circ} \mathrm{C}\right)$. Arrows indicate the median values. - - - : detection limit.

a moderate work in cold air $\left(52.3(42.2-66.4) \times 10^{6}\right.$ cells $\cdot \mathrm{L}-$ 1) compared with the normal indoor temperature $(34.8$ (23.9-41.0) $\times 10^{6}$ cells $\cdot \mathrm{L}^{-1}, \mathrm{p}<0.05$, fig. 1$)$. No significant change in the number of lymphocytes was found (fig. 1). There was no significant difference with regard to albumin concentration in BAL fluid after cold air exposure (35.2 (29.5-56.0) $\mathrm{mg} \cdot \mathrm{L}^{-1}$ ) and room temperature (35.4 $\left.(32.2-37.8) \mathrm{mg} \cdot \mathrm{L}^{-1}\right)$ or the IL-8 concentration in BAL fluid, (14.6 (11.6-40.2) ng. $\mathrm{L}^{-1}$ at normal indoor air and 23.6 (10.7-49.1) ng. $\mathrm{L}^{-1}$ after cold air exposure (fig. 2). With the exception of one subject, all measurements of IL-6 and TNF $\alpha$ in BAL fluid after exposure to room temperature and cold air were below the detection limit ( 3 and $0.5 \mathrm{ng} \cdot \mathrm{L}^{-1}$, respectively). The MPO levels in BAL fluid were $2.4(<1.6-4.6) \mu \mathrm{g} \cdot \mathrm{L}^{-1}$ after exposure to room temperature and $3.1(<1.6-3.1) \mu \mathrm{g} \cdot \mathrm{L}^{-1}$ after exposure to cold air ( $\mathrm{p}=0.2$, fig. 2). ECP in BAL fluid was below the detection limit in all samples after exposure to room temperature and cold air.

Lymphocytes markers for T-cell subsets and for T-cell activation in BAL fluid did not differ significantly between the two experimental days (table 2).

The total cell or neutrophil concentration did not change significantly in nasal lavage fluid 4 and $20 \mathrm{~h}$ after exposure at any day (fig. 3). Prior to the experiment, the concentration of total cells was $4.3(2.2-25.3) \times 10^{6}$ cells $\cdot \mathrm{L}^{-1}$. The corresponding concentration of neutrophils was 3.1

Table 2. - Lymphocyte characteristics in bronchoalveolar lavage (BAL) after a moderate work in room temperature and in cold air

\begin{tabular}{lccccc}
\hline $\begin{array}{l}\text { Lymphocyte marker } \\
\text { in BAL }\end{array}$ & \multicolumn{2}{c}{$\begin{array}{c}\text { Room } \\
\text { temperature }\end{array}$} & Cold air & $\begin{array}{c}\text { p- } \\
\text { value }\end{array}$ \\
\hline CD3 & 82 & $(75-88)$ & $8.7(83-88)$ & 0.093 \\
CD19 & 0.6 & $(0-0.8)$ & 0 & $(0-0.1)$ & 0.027 \\
CD4 & 57 & $(54-71)$ & 56 & $(46-65)$ & 0.069 \\
CD8 & 26 & $(13-29)$ & 25 & $(18-31)$ & 0.069 \\
CD4/CD8 & $2.1(1.9-5.9)$ & 2.2 & $(1.6-3.8)$ & 0.036 \\
CD3/CD69 & 35 & $(25-54)$ & 28 & $(18-34)$ & 0.401 \\
\hline
\end{tabular}

Data are presented as medians and 25th-75th percentiles in parentheses. All parameters, except for CD4/CD8, are expressed as a percentage of total lymphocytes. No significant differences were found (with the Bonferroni correction for multiple comparisons, a p-value $<0.008$ is required for significance at the $5 \%$ level).
$(0.5-23.4) \times 10^{6}$ cells $\cdot \mathrm{L}^{-1}$. The baseline albumin concentration in nasal lavage fluid was $14.0(12.0-23.2) \mathrm{mg} \cdot \mathrm{L}^{-1}$ and did not change significantly on either day (fig. 3 ). The pre-exposure concentration of IL-8 in nasal lavage fluid was $255(150-432) \mathrm{ng} \cdot \mathrm{L}^{-1}$. No significant changes in nasal lavage IL-8 concentration were found following exposure (fig. 3).

\section{Discussion}

It has recently been described that cross-country skiers have an increased prevalence of asthma symptoms [1,2] and bronchial hyperresponsiveness to methacholine [2,9]. No conclusive data regarding the occurrence of airway inflammation in the skiers have yet been published. Thus, long-term repeated heavy exposure, i.e. high ventilation, to cold air may lead to asthma (or an asthma-like condition). The present results demonstrate that a few hours exposure to cold air increases the number of inflammatory cells (granulocytes and macrophages) in the lungs. It seems probable therefore, that an increased number of cells in the lungs following a short exposure to cold air is a normal response in healthy subjects. However, heavy, repeated exposure to cold air may lead to asthma, which is most probably accompanied by chronic airway inflammation. The mechanisms by which a normal stimulus (cold air) that creates a normal response (increase in cell number) becomes an abnormal stimulus that induces a pathological (asthmatic) response are not known.

Inspired air is of body temperature and almost $100 \%$ relative humidity when reaching the alveolar space [10]. This condition is met when the inspired air passes through the larger airways [11], indicating that substantial heat and water loss occurs in this part of the airway tree. Inhalation of cold air clearly induces an increase in the number of inflammatory cells as assessed by BAL, which predominantly reflects the situation at the alveolar level. The BAL technique used in our study excludes any possibility of evaluating to what extent the cellular findings also represent cellular occurrence in the larger airways. It is possible, however, that our finding in BAL reflect, to a certain extent, the cellular contribution from the larger airways since the stimulus, i.e. the cold air, only affects this part of the airway tree. 

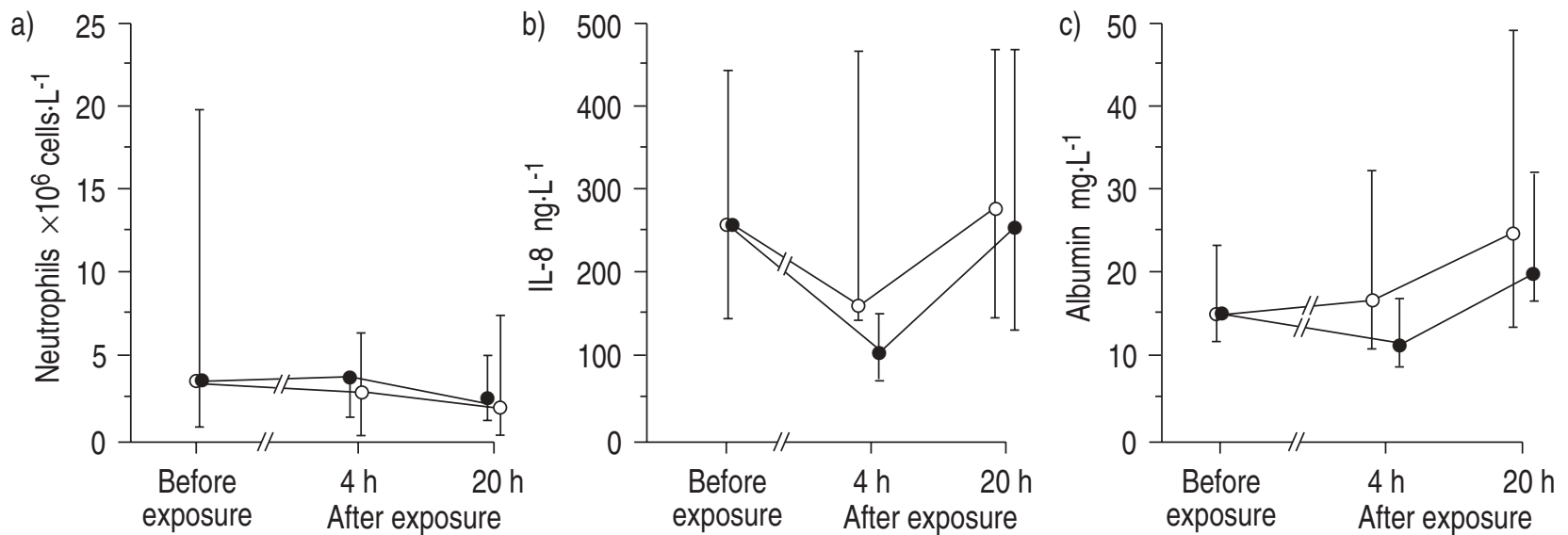

Fig. 3. - a) Neutrophils, b) interleukin (IL)- 8 and c) albumin concentration in nasal lavage fluid before exposure and 4 and $20 \mathrm{~h}$ after moderate exercise at $-23(\bullet)$ and $+22^{\circ} \mathrm{C}(\mathrm{O})$. The median and 25 th-75th percentiles are shown.

The mechanisms by which granulocytes and macrophages enter the lower airways following inhalation of cold air are unclear. In the present study, IL-8, as a possible neutrophil chemoattractant, was measured in BAL fluid but was found to be at a similar level after cold air exposure as after a moderate work in room temperature. After other types of exposure like inhalation of organic dust, IL-8 in BAL fluid is approximately doubled $20 \mathrm{~h}$ after exposure [12]. Because of the low number of participants, the power for detecting a doubling of the IL-8 levels in BAL fluid was only $65 \%$ (at $\alpha=0.05$ ) in the present study. It cannot be excluded that an early production of this chemokine may occur and may not be detected due to normalization in the BAL fluid obtained 1 day after exposure. Due to the low statistical power and the lack of a time-kinetic approach, a possible role for IL-8 following cold air exposure cannot be excluded from the present study.

In the upper airways, the cellular composition of lavage fluid obtained after exposure to cold was similar to that found after normal indoor exposure. It is unlikely that an early influx of neutrophils into the upper airways would not be detected in the lavage performed after $4 \mathrm{~h}$. The reason for the discrepancy between upper and lower airways in this respect is probably due to different exposures. The subjects will breath through the nose during rest (when the pulmonary ventilation is low) and predominantly through the mouth during exercise (when the pulmonary ventilation is high). This implies that the upper airways are probably less exposed to cold air than the lower airways during exercise. We cannot exclude, from the present results, therefore, the possibility that identical exposure to cold air leads to different consequences in the upper and lower airways.

The albumin concentration was not increased after cold-air inhalation in nasal lavage (4 and $20 \mathrm{~h}$ after exposure) or in BAL fluid ( $20 \mathrm{~h}$ after exposure). The statistical power for detecting a doubling of the albumin concentration in nasal lavage fluid was only $56 \%$ (at $\alpha=0.05$ ) where as there was a power of $80 \%$ to detect a $30 \%$ change in BAL fluid albumin concentration $(\alpha=0.05)$. Although the increase of cells in the lower airways indicates an inflammatory reaction, we found no evidence for an increased plasma exudation, as assessed by albumin concentration in BAL fluid. The finding of unchanged lavage albumin levels does not necessarily mean that the exposure does not lead to plasma exudation. Thus, it has been found that bronchial allergen challenge did not increase the lavage fluid concentration of albumin, although other inflammatory parameters, including fibrinogen concentration in lavage fluid, were increased [13]. In the present study, there is also a possibility that the BAL, performed $20 \mathrm{~h}$ after the exposure, is too late to detect any early, transitory albumin increase.

We found no evidence for the involvment of proinflammatory cytokines in the lower airway reaction, and the concentration of TNF $\alpha$ and IL- 6 in BAL fluid remained below the detection limit in all but one subject after both exposures. Eosinophilic cationic protein, a marker for eosinophilic granulocyte activation, was below the detection limit in all subjects following both exposures, indicating that eosinophils may not be involved in the airway reaction to cold air in healthy subjects. More surprisingly, myeloperoxidase did not change significantly in BAL fluid, although we had a low statistical power to detect it $(<50 \%$ to detect a doubling of the concentration at $\alpha=0.05$ ). It thus seems as if cold air induces increased numbers of granulocytes in BAL fluid without any activation of the cells. As for the other soluble products, an increased concentration of cytokines and activation markers may have occurred at an earlier time point and become normalized at the time for postexposure BAL. A possible involvement of pro-inflammatory cytokines and cellular activation markers could thus not be excluded and should be investigated in a study designed to follow the postexposure time course for the different markers. It would not be possible to explore this issue further by increasing the number of participants in the present study.

Previous studies have demonstrated that a short exposure to cold air increases the bronchial responsiveness to histamine [3]. It would have been of interest to determine how the exposure in the present study influenced the bronchial responsiveness. However, we deliberately refrained from performing a bronchial provocation since it could not be excluded that the small changes that we anticipated to occur in the lavage fluid would have been influenced by the bronchial challenge (or vice versa).

In conclusions, we have found that a short-time exposure to cold air induces an increase in the number of inflammatory cells in the lower airways. We have, however, 
not been able to demonstrate any involvement of other inflammatory indices such as plasma leakage, involvement of pro-inflammatory cytokines or cellular activation. It is thus possible that the increased number of granulocytes and macrophages following exposure to cold air only reflects an impaired adhesion of these cells to the airway epithelium and that the cells thereby become more easily recruited by bronchoalveolar lavage. The importance of this finding and possible links to the development of asthma (or an asthma-like condition) in heavy exposed subjects such as cross-country skiers (and possibly outdoor workers) needs to be elucidated further.

Acknowledgement: The expert assistance of S. Siljerud and A. Ek is gratefully acknowledged. The authors thank M. van Hage-Hamsten for performing the ECP analyses.

\section{References}

1. Larsson L, Hemmingsson P, Boethius G. Self-reported obstructive airway symptoms are common in young crosscountry skiers. Scand J Med Sci Sports 1994; 4: 124-127.

2. Larsson K, Ohlsén P, Larsson L, Malmberg P, Rydström P$\mathrm{O}$, Ulriksen $\mathrm{H}$. High prevalence of asthma in cross country skiers. Br Med J 1993; 307: 1326-1329.

3. Amariv I, Plit M. Temperature and relative humidity response to inhaled histamine in normal subjects. Am Rev Respir Dis 1989; 140: 1416-1420.
4. McFadden ER. Hypothesis: exercise-induced asthma as a vascular phenomenon. Lancet 1990; 335: 880-883.

5. Anderson SD. Issues in exercise-induced asthma. J Allergy Clin Immun 1985; 76(6): 763-772.

6. Bascom R, Pipkorn U, Lichtenstein LM, Naclerio RM. The influx of inflammatory cells into nasal washings during the late response to antigen challenge. Am Rev Respir Dis 1988; 138: 406-412.

7. Pipkorn U, Karlsson G, Enerbäck L. A brush method to harvest cells from the nasal mucosa for microscopic and biochemical analysis. J Immunol Meth 1988; 112: 37-42.

8. Wang Z, Larsson K, Palmberg P, Malmberg P, Larsson P, Larsson L. Inhalation of swine dust induces cytokine release in the upper and lower airways. Eur Respir J 1997; 10: 381-387.

9. Sue-Chu M, Larsson L, Bjermer L. Prevalence of asthma in young cross country skiers in central Scandinavia: Differences between Norway and Sweden. Respir Med 1996; 90: 99-105.

10. Gilbert IA, Fouke JM, McFadden ER. Heat and water flux in the intrathoracic airways and exercise-induced asthma. $J$ Appl Physiol 1987; 63: 1681-1691

11. Daviskas E, Gonda I, Anderson SD. Mathematical modeling of heat and water transport in human respiratory tract. J Appl Physiol 1990; 69: 362-372.

12. Larsson B-M, Palmberg L, Larsson K, Malmberg P. Effect of exposure to swine dust on levels of IL-8 in airway lavage fluid. Thorax 1997; 52: 638-642.

13. Salomonsson P, Grönneberg R, Gilljam H, et al. Bronchial exudation of bulk plasma at allergen challenge in allergic asthma. Am Rev Respir Dis 1992; 146: 1535-1542. 